\section{ITW Dynatec erhält IDEA Achievement Award}

m Rahmen der International Engineered Fabrics Conference \& Expo - kurz: IDEA - wurde ITW Dynatec bereits zum zweiten Mal in Folge mit dem Preis für die „Innovativste Technologie“ ausgezeichnet.

Gewürdigt wurde die sogenannte Surge Technologie in der Kategorie „IDEA Achievement Awards“, gefördert von der INDA (Association oft he Nonwovens Fabrics Industry).

Besonderes Merkmal der prämierten Applikationsmethode Surge ist die Kombination von Auftragsgewichten. Damit wird Anwendern erstmals die Möglichkeit geboten, verschiedene Klebstoffgewichte auf ein und demselben Substrat aufzutragen.

Außergewöhnliche Klebstoffeinsparungen, eine signifikante Verringerung der Abfallmengen und eine verbesserte Produktivität werden als Vorteile genannt.

Weitere Infos: ITW Dynatec, Tel.: +1 800-966-6358,

info@itwdynatec.com,www.itwdynatec.com

\section{Branchenwissen in Sachen Ressourceneffizienz}

D as VDI Zentrum Ressourceneffizienz, eine 2009 mit Mitteln des Bundesumweltministeriums gegründete Klimaschutzinitiative, hat für die Branchen Metallverarbeitung, Oberflächenbeschichtung und Kunststoffverarbeitung das verfügbare Fachwissen in Sachen Ressourceneffizienz auf einer DVD gebündelt.

Die Informationen wurden für jeden dieser drei Bereiche entlang der jeweiligen Prozesskette systematisiert. Mit Ressourcenchecks können Unternehmen Einsparpotenziale bei den Materialkosten aufdecken und sich Impulse für mögliche Effizienzprojekte holen. Neben einem Basischeck werden weitere Vertiefungsmodule angeboten, die speziell auf die Anforderungen der drei Branchen zugeschnitten sind.

Wie Ressourceneffizienz konkret in der Praxis aussehen kann, zeigen Erfolgsgeschichten von Unternehmen des gewählten Wirtschaftszweiges. Anschauliche Kurzfilme über Best-Practice-Beispiele runden das Informationsangebot ab.

Die DVD steht Unternehmen kostenlos zur Verfügung: info@vdi-zre.de

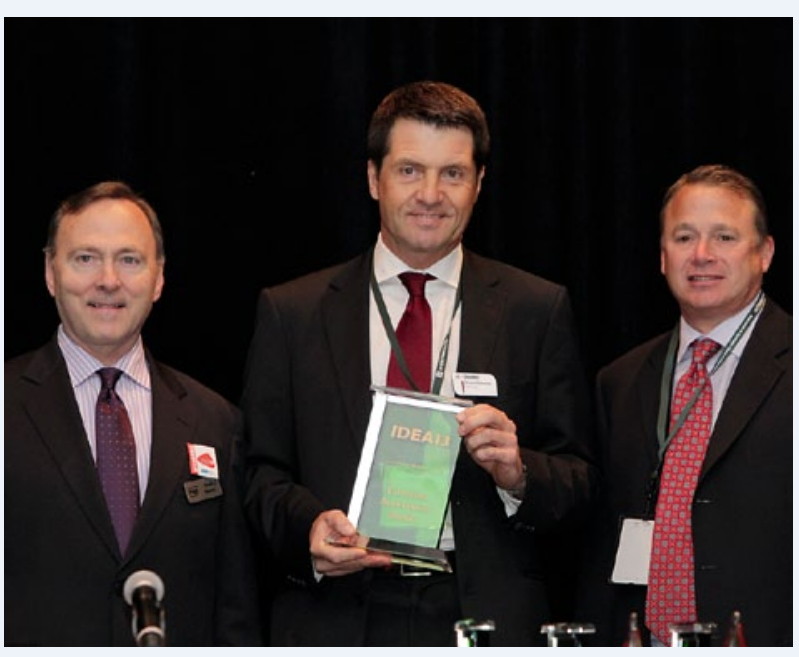

„Es ist lohnend, zu sehen, dass unser Einsatz einen echten Mehrwert für den Kunden darstellt", so Christof Schotten, Vice President/General Manager (Mitte) von ITW Dynatec, nach der Preisverleihung auf der IDEA 2013 in Miami.

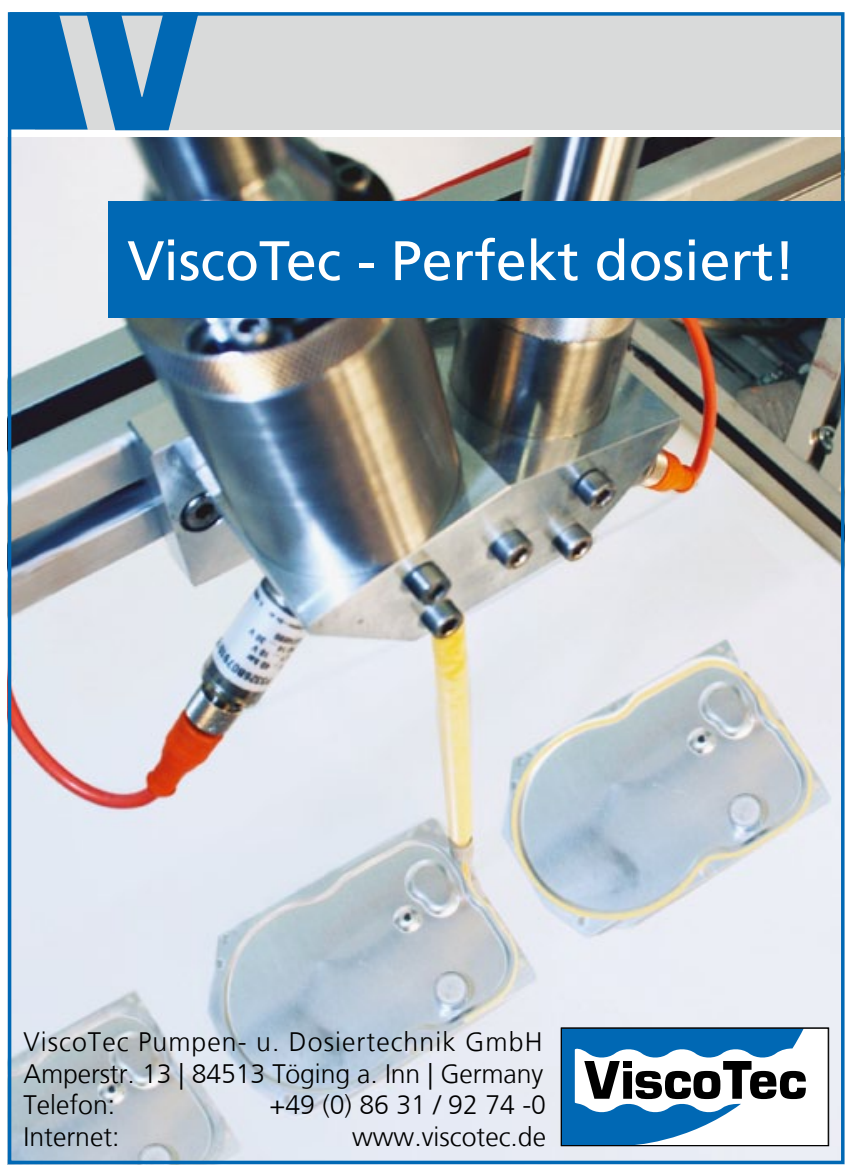

